The Expansion of College Education in the United States:

Is There Evidence of Declining Cohort Quality?

Chinhui Juhn

Dae-Il Kim

and

Francis Vella*

RRH: JUHN, KIM, \& VELLA: EXPANSION OF COLLEGE EDUCATION 
JEL I20, J24, J31

\title{
The Expansion of College Education in the United States: Is There Evidence of Declining Cohort Quality?
}

This paper documents the expansion of college education in the U.S. and examines to what extent the increase in the number of college graduates may have lead to a decline in the average quality of college graduates. Using the 1940-1990 Census, we compare across birth year cohorts with varying levels of college completion. We find some weak evidence that college graduate men from highly educated cohorts earn a relatively smaller wage premium even controlling for the relative supply effect. However, these cohort quality effects account for only a small fraction of the recent fluctuation in the college wage premium.

\author{
Chinhui Juhn \\ Department of Economics \\ University of Houston \\ Houston, Texas 77204-5882 \\ Dae-il Kim \\ School of Economics \\ Seoul National University \\ Seoul 151-742, Korea \\ Francis Vella \\ Department of Economics \\ European University Institute \\ Villa San Paolo \\ Via della Piazzuola, 43 \\ 50133 Firenze \\ Italy
}




\section{INTRODUCTION}

In 1940, approximately 5 percent of men aged 20-64 were college graduates. By 1990, the fraction with a college degree had more than quadrupled to 22.6 percent. Conversely, more than 70 percent of men aged 20-64 had not finished high school in 1940. By 1990, the fraction of the male population who were high school dropouts had dipped below 20 percent. These changes imply that there has been an enormous increase in the supply of skilled workers in the U.S. economy over the past five decades. The magnitude of these changes also suggests that the composition of these groups, in terms of their underlying ability and talents, have also changed, making it difficult to compare these groups over time.

In this paper we focus on the expansion of college education. We ask whether the increase in the number of college graduates over time lead to a decline in the average ability of college graduates. Following Becker (1967), we introduce a simple model of human capital accumulation with individuals who differ in ability and borrowing costs. Under the assumption that the ability distribution is fixed and the more able attend college, we examine the conditions under which a rising share of college graduates leads to a decline in the average ability of the college educated group.

The relationship between the expansion of higher education and the average ability of college attendees was explored by Taubman and Wales (1972) in their well-known study. Putting together evidence from a variety of test score studies, they reported that the average aptitude of those who attended college actually rose relative to those who did not attend college. We take an alternative, more aggregate approach in examining the expansion of college 
education and average ability in this paper. Using the 1940-1990 Census, we compare across cohorts with different levels of educational attainment. We ask whether college graduates from more educated cohorts receive a smaller college premium and locate in less skilled occupations, even controlling for the relative supply effect. Thus, we do not observe changes in ability directly, but infer changes in ability through changes in relative wages and occupational distribution.

There are several reasons why we view this alternative approach as useful. First, the test score studies are based on different tests administered in different states which raises questions about the comparability of the results over time. Second, the test scores are often available only for those who finished high school. Since the selection of high school graduates is also changing, it is difficult to infer changes in ability of college graduates. Third, test scores typically have little explanatory power in earnings regressions, suggesting other dimensions of ability are important for earnings determination. Finally, many of these studies refer to the first half of the twentieth century while we extend the analysis to the more recent period.

A number of recent papers (Murphy and Welch (1992), Katz and Murphy (1992), Topel (1997), Autor, Katz, and Krueger (1998)) have argued that the rapid increase in the share college graduates depressed college premiums in the 1970s. Welch (1979), Berger (1985) and Card and Lemieux (2000) show that these declines in college premiums were particularly associated with the baby-boom cohorts who entered college in record numbers. In this paper we examine to what extent these "cohort" effects may reflect a decline in quality associated with an accelerated pace of college attendance.

To preview our results, we find a small and marginally significant cohort quality effect 
which suggests that a 10 percent increase in the cohort-specific college share leads to a 0.6 percent decline in the college premium, holding everything else constant. These results suggest that changes in cohort quality played a minimal role in the recent period, with relative supply and demand shocks accounting for most ( 87 percent) of the variation in relative wages. These small relative wage effects related to changes in ability are in line with evidence from test scores reported in Murnane, Willett and Levy (1995). ${ }^{1}$

Section II begins by describing the aggregate changes in educational attainment over the period 1940-1990. While we concentrate mostly on prime-age men in this paper, we also report changes in educational attainment of women. Section III presents our human capital framework. Section IV presents the results from our cohort-level regressions. Section V presents a summary of our main findings.

\section{THE EXPANSION OF COLLEGE EDUCATION IN THE U.S.}

One of the most notable changes in the U.S. labor market in the past several decades has been the increase in educational attainment of its labor force. In this section we document this change using the 1/100 sample of the 1940-1990 Public Use Micro Samples (PUMS). To describe changes in the education distribution over time we use an inclusive sample of men and women who were 20-64 years old. Our regressions results are based on men who are older, 2564 years old. We restrict our analysis to the older group since they are more likely to have completed their education and we examine men in order to ensure consistent labor market attachment. To calculate labor quantities, we include men 25-64 years old who were employed 
during the survey week but did not work in agriculture. To calculate wages, we chose a more select sample of these men who were wage and salary workers, worked full-time, worked at least 40 weeks, and earned at least $1 / 2$ the legal federal minimum weekly wage. Our wage measure is the weekly wage calculated as annual earnings divided by weeks worked. Annual earnings were deflated using the PCE deflator from the national product and income accounts.

Table 1 reports shares of men and women of prime working age (20-64 years old) in four education categories: less than high school, high school graduate, some college, and college graduate. In 1940, as much as 74 percent of working-age men had less than a high school degree while 5.4 percent had a college degree. By 1990, less than 20 percent were high school dropouts while 22.6 percent college graduates. ${ }^{2}$ The bottom panel of table 1 reports the educational attainment of women. The table shows that there has been an equally dramatic increase in the educational attainment for women although women are still slightly less likely to be college graduates than the men. For example, even in 1990, the fraction of women who are college graduates is 18.6 percent compared to 22.6 percent for men. However, as will be illustrated in figure 3 , the educational attainment of the most recent cohorts presents a different picture in that women are now more likely to be college graduates than their male counterparts.

[Table 1 here]

Figure 1 and figure 2 present educational attainment by birth-year cohort for men and women respectively. The different panels present shares of the four education groups: less than high school, high school graduate, some college, and college graduate. The figures are based on data from the 1940-1990 Census. As is apparent from the figures, men and women in any particular birth-year cohort acquire more schooling as they age. For example, a greater fraction 
of the cohort born in 1920 are college graduates in the 1950 Census (when the cohort is 30 years old) as compared to the 1940 Census (when the cohort was only 20 years old). To extrapolate the shares in each education category for the most recent cohorts, we run the following simple regression using cohort-level data:

$$
\mathrm{e}_{\mathrm{ct}}=\alpha \mathrm{A}_{\mathrm{ct}}+\gamma_{\mathrm{c}}+\mu_{\mathrm{at}}+\epsilon_{\mathrm{ct}}
$$

where $e_{c t}$ is the share of the cohort in the education category, $A_{c t}$ is a quartic in age, $\gamma_{c}$ is the cohort specific effect measured by birth-year cohort dummies, $\mu_{\mathrm{at}}$ are year-"young" interaction dummies where "young" is defined as 20-24 years old and $\epsilon_{\mathrm{ct}}$ is the error term. We run these regressions for each of the four education groups and graph the shares predicted at age 35 .

[Figure 1 and Figure 2 here]

Figures 1 and 2 show that the fraction who had less than a high school degree fell dramatically from over 80 percent among the 1880 birth cohort to approximately 10 percent among the most recent cohorts. On the other hand, the fraction who are college graduates increased from less than 5 percent to over 30 percent among the most recent cohorts. For men, college graduation rates peaked with the 1948-1950 birth cohorts (among whom approximately 31 percent were college graduates) and declined among the more recent cohorts. It is interesting that for women, college graduation rates began to accelerate starting with later cohorts and there is little evidence of a decline among the more recent cohorts.

The trend in college enrollment in the most recent period is better illustrated in figure 3 which is based on March CPS data. ${ }^{3}$ The figure reports the fraction of 20-24 year old men and 
women who are either college graduates or still enrolled in school during the survey years 19681995. The left panel of figure 3 shows that college enrollment peaked for men in the late 1960s with the cohorts born in the late 1940s, fell to approximately 24 percent in 1981 and has increased again in the most recent period most probably in response to the rise in the college premium. College enrollment among women (illustrated in the right panel of figure 3) has more or less increased continuously throughout the 1970s and the 1980s and has surpassed the enrollment rates observed among men in the most recent period.

[Figure 3 here]

These figures illustrate the substantial variation in college completion rates across birth cohorts, particularly among men. The differences between men and women also suggest that factors such as the GI Bill during the 1940s and the deferment of the draft during the Vietnam War may have played important roles. It is these types of differences in college enrollments across birth cohorts that will be the basis of our empirical work in section IV.

\section{MODEL OF HUMAN CAPITAL ACCUMULATION AND COHORT QUALITY}

To provide a framework for discussion and for our empirical work, we examine a simplified version of the Becker (1967) model of human capital accumulation. This model has been reformulated by Rosen (1977) and generalized to incorporate heterogeneous human capital in Willis and Rosen (1979). Most recently it has been revived to discuss biases in estimating returns to schooling from cross-sectional data (Card (1994) and Lang (1994)). Our purpose here is to characterize, within the context of this well-known model, the conditions under which we 
can expect the size and average ability of the college educated group to negatively co-vary. The share of college educated can increase for a variety of reasons such as an increase in price of skills acquired in college, decline in tuition costs, and decline in the cost of borrowing funds which may be affected by government loan or subsidy programs. In our discussion below we consider these different cases. ${ }^{4}$

Individuals maximize the present value of life time earnings and compare the benefits and costs in deciding whether to obtain a college degree. The discounted benefit of college education net of foregone earnings, $R(\theta, r, \lambda)$, depends on the price of the skill acquired in college, $\theta$, the interest (discount) rate, $r$, and the ability of the individual, $\lambda . \mathrm{R}(\theta, \mathrm{r}, \lambda)$ is increasing in $\theta$, decreasing in $\mathrm{r}$, and increasing in $\lambda\left(\mathrm{R}_{\theta}>0, \mathrm{R}_{\mathrm{r}}<0\right.$, and $\left.\mathrm{R}_{\lambda}>0\right)$. We denote the direct costs of college (such as tuition) as $\beta$, and assume that it is positive and independent of ability. ${ }^{5}$

A worker of ability $\lambda$ will decide to enter college if the benefit exceeds the cost, $\mathrm{R}(\theta, \mathrm{r}, \lambda)>\beta$. At each interest rate, $\mathrm{r}$, one can define a cut-off ability level $\lambda^{*}$ such that $\mathrm{R}\left(\theta, \mathrm{r}, \lambda^{*}\right)=\beta . \lambda^{*}$ is a function of $\theta, \mathrm{r}$, and $\beta$. Further, $\partial \lambda * / \partial \theta=-\mathrm{R}_{\theta} / \mathrm{R}_{\lambda}<0$, $\partial \lambda * / \partial \beta=1 / \mathrm{R}_{\lambda}>0$, and $\partial \lambda * / \partial \mathrm{r}=-\mathrm{R}_{\mathrm{r}} / \mathrm{R}_{\lambda}>0$. In other words, the cut-off ability declines as the price of college skills increases, and rises with increases in tuition costs and the interest rate. Denoting the joint population density of interest rate and ability as $\mathrm{h}(\mathrm{r}, \lambda)$, the size of the college going population $(\mathrm{N})$ and their average ability $(\operatorname{Ec}(\lambda))$ are obtained as in equation (2).

$$
N=\int_{0}^{\bar{r}} \int_{\lambda^{*}}^{1} h(r, \lambda) d \lambda d r, \quad E_{c}(\lambda)=1 / N \int_{0}^{\bar{r}} \int_{\lambda^{*}}^{1} \lambda h(r, \lambda) d \lambda d r
$$


In the above, the interest rate is assumed to take a value between 0 and a finite upper-bound $\bar{r}$ $<\infty$.

Case 1: Everybody faces the same interest rate at $r^{*}$.

When everybody faces the same interest rate, the joint density can be denoted as the marginal density, $h(\lambda)$, and the number of college entrants and their average ability may be calculated by integrating only over ability, $\lambda$. Under this assumption, now consider an increase in the college skill premium, $d \theta>0$. The change in the skill premium induces a change in the cutoff ability level, $\lambda^{*}$, and it can be shown that $\partial \mathrm{N} / \partial \theta=-\mathrm{h}\left(\lambda^{*}\right) \cdot \partial \lambda^{*} / \partial \theta>0$. That is, college enrollment increases. At the same time, $\partial \operatorname{Ec}(\lambda) / \partial \theta=\left(\operatorname{Ec}(\lambda)-\lambda^{*}\right) \mathrm{h}\left(\lambda^{*}\right) / \mathrm{N} \cdot \partial \lambda^{*} / \partial \theta<0$, and the average ability of college entrants declines. An increase in returns to schooling induces relatively low-ability workers to enter college. In this simple case, we will see a negative relationship between the number of college graduates and their average ability. An increase in tuition costs that does not vary with ability, $d \beta>0$, would be the mirror image of the case described above. College enrollment will decline and average ability will rise. These simple cases are illustrated in figure 4.

[Figure 4 here]

Case 2 : Individuals face different interest rates due to borrowing constraints.

In the presence of imperfect capital markets, individuals can also differ in terms of their 
access to funds. It may be the case, for example, that individuals from wealthier families have lower cost of borrowing than individuals from poorer families. In this case, the cut-off ability $\lambda^{*}(\theta, \beta, \mathrm{r})$ rises with $\mathrm{r}$ and it is possible that very high ability individuals will choose not to attend college when faced with very high borrowing costs. If a given increase in the returns to college skills, $\theta$, or reduction in tuition costs, $\beta$, leads to greater adjustments among individuals facing higher borrowing costs, it is at least theoretically possible that these marginal entrants will actually raise the average ability of the college educated group. In the following we characterize the conditions under which such cases can be ruled out.

The impact of a change in the skill price on the number of college entrants and their ability are obtained by differentiating (2) with respect to $\theta$ as in the following:

$$
\begin{aligned}
\partial N / \partial \theta & =\int_{0}^{\bar{r}}-h\left(r, \lambda^{*}\right) \partial \lambda^{*} / \partial \theta d r>0 \\
\partial E_{c}(\lambda) / \partial \theta & =1 / N \int_{0}^{\bar{r}}\left\{E_{c}(\lambda)-\lambda^{*}\right\} \partial \lambda^{*} / \partial \theta h\left(r, \lambda^{*}\right) d r
\end{aligned}
$$

The first partial derivative in equation (3), $\partial N / \partial \theta$, has an unambiguously positive sign as $\lambda *$ is a decreasing function of $\theta$. An increase in the college skill premium increases the number of college entrants.

If the second partial derivative in equation (3) is negative, this would lead to negative covariation between the size and average ability of the college educated group. Since $\partial \lambda * / \partial \theta<0$, the second partial derivative in equation (3) is negative when $\operatorname{Ec}(\lambda)-\lambda *$ is positive at all levels of r. In other words, the cut-off ability level is below the average ability of college educated group 
at all levels of $r . \operatorname{Ec}(\lambda)-\lambda *$ is likely to be positive at all levels of $r$ if the cut-off ability does not vary much across interest rates, i.e. $\partial \lambda * / \partial \mathrm{r}$ is positive but small. Since $\partial \lambda * / \partial r=-\mathrm{R}_{\mathrm{r}} / \mathrm{R}_{\lambda}$, this condition is satisfied when the comparative advantage in returns to higher ability individuals, $\mathrm{R}_{\lambda}$, is large relative to the disincentive effect of the higher interest rate. In other words, ability plays a larger role in determining who acquires education and large differences in $r$ generate only small differences in $\lambda^{*}$. This, in effect, gets us close to case 1 and an increase in $\theta$ will most likely lead to a decline in average ability.

Another component is the adjustment $\partial \lambda * / \partial \theta$ at high and low interest rates. If $|\partial \lambda * / \partial \theta|$ decreases with $r$ so that adjustments at high interest rates are smaller than those at lower interest rates, this reduces the likelihood of an increase in average ability.

Finally, the shape of the joint density, $\mathrm{h}(\mathrm{r}, \lambda)$, matters. The negative relation between size and average ability of the college group is more likely if the joint density, $h(r, \lambda)$ has little mass at high interest rates and high ability. This effectively reduces the importance of the adjustment at high ability-high interest rate margins. We have assumed so far in our discussion that the distribution of ability and borrowing costs are uncorrelated in the population. Recent papers by Cameron and Heckman (1998) and Cameron and Taber (2000) suggest that this correlation may be negative. To the extent that family income affects ability directly rather than through borrowing costs, this would strengthen the negative relationship between size and average ability.

We have so far examined how college enrollment and average ability changes in response to an increase in returns to college, $d \theta>0$, or its mirror image, reduction in tuition costs, $d \beta<0$. It is also interesting to consider whether size and ability would negatively co-vary when borrowing costs, $r$, change due to government loans and subsidies. We examine this case in the appendix 
and focus on two different types of subsidies, a general subsidy that lowers the cost of funds for everyone, and a narrower subsidy that targets those individuals who would otherwise face very high interest rates. Our conclusions are intuitive and not very surprising. A general subsidy that lowers $\mathrm{r}$ for everyone would lead to an increase in college enrollments and an unambiguous decline in average ability. It is possible that a targeted subsidy that only affects those who initially face very high interest rates may lead to an increase in average ability. This is due to the fact that these individuals at the margin are high ability individuals, and inducing them to enroll in college may actually increase the average ability of the college population. ${ }^{6}$

\section{THE EFFECT OF COHORT-SPECIFIC COLLEGE SHARE ON THE RELATIVE WAGE OF COLLEGE GRADUATES}

In this section, we examine the relationship between rising college share and average ability of the college educated group using cohort-level data from the 1940-1990 Census. Our analysis covers a long span of time using comparable data which is an advantage. A disadvantage is that we do not have direct measures of ability and therefore must infer changes in ability through changes in wages. More specifically, we examine whether college graduate men from highly educated cohorts earn a smaller college premium, holding constant other variables which also affect the college premium.

In what follows, we first aggregated the data by census year, single year of age, and by college completion. We ran regressions in changes using weighted least squares on this aggregate level data.. Our dependent variable is the decade change in log relative wage of college graduates at different ages. In other words, we compare the college premium received by, for 
example, 40 year-old college graduate men in year $t$ with the college premium received by 40 year-old college graduate men 10 years earlier, thereby utilizing between-cohort variation in the data. Our main regressor of interest is the between cohort log differences in the share who went to college, $\Delta \log \left(\mathrm{N}_{\mathrm{ac}} / \mathrm{N}_{\mathrm{a}}\right)$. We use predicted college share of each cohort at age 35 as specified in equation (1) rather than actual observed shares at time t, so as to not confound the effects of cohort quality and relative supply. The variation in the data that we exploit is illustrated in figure 5 which graphs decade log changes in relative wage and college share at different age levels over the period 1979-1989. The picture illustrates the strong negative correlation between changes in relative wage and college share during this latter period. Although they are less pronounced, negative correlations also exist in other periods as illustrated in figure 6.

[Figure 5 and Figure 6 here]

To the extent that workers in different education groups are imperfect substitutes for each other, the increase in college share will negatively impact the relative wage of college graduates regardless of the quality effect. We control for relative supply in three alternative ways. In the first specification, we include year dummies to control for aggregate supply and demand shocks and run the following regression

$$
\Delta \log \left(W_{a c t} / W_{a t}\right)=\beta_{1} \Delta \log \left(N_{a c} / N_{a}\right)+\beta_{2} \Delta \log \left(N_{a c t} / N_{c t}\right)+\tau_{t}+\delta_{a}+\epsilon_{a t}
$$

where a indexes age and $\mathrm{c}$ indexes college graduate. This assumes that workers in different age groups are perfect substitutes for each other so that an influx of new college graduates will have an equally adverse impact on all college graduates and the year dummies control for this effect. 
As indicated in equation (4), we also include a control for overall cohort size, $\Delta \log \left(\mathrm{N}_{\mathrm{act}} / \mathrm{N}_{\mathrm{ct}}\right)$, and dummies for young (25-35) and middle age (35-50).

In the second specification, we control for changes in the relative supply of workers with different education levels, high school dropouts $\Delta \log \left(\mathrm{N}_{\mathrm{d} t} \mathrm{~N}_{\mathrm{t}}\right)$, high school graduates, $\Delta \log \left(\mathrm{N}_{\mathrm{ht}} / \mathrm{N}_{\mathrm{t}}\right)$, and college graduates, $\Delta \log \left(\mathrm{N}_{\mathrm{ct}} / \mathrm{N}_{\mathrm{t}}\right)$. The relative supply of college graduates is the actual share observed in year $\mathrm{t}$, rather than the predicted share at age 35 which is our main cohort quality variable. However, the two variables are highly co-linear, making it difficult to separately identify the two effects. We follow the strategy suggested in Welch (1979) where we define relative supply as the weighted average around a given age group. The supply of college graduates, for example, is defined as $\mathrm{N}^{*}$ act $=1 / 9 *\left(\mathrm{~N}_{\mathrm{a}-2, \mathrm{ct}}+2 * \mathrm{~N}_{\mathrm{a}-1, \mathrm{ct}}+3 * \mathrm{~N}_{\mathrm{act}}+2 * \mathrm{~N}_{\mathrm{a}+1, \mathrm{ct}}+\mathrm{N}_{\mathrm{a}+2, \mathrm{ct}}\right)$. This assumes that workers in nearby age groups are closer substitutes. More specifically, we run the following regression for this specification

$$
\begin{aligned}
\Delta \log \left(W_{a c t} / W_{a t}\right)= & \beta_{1} \Delta \log \left(N_{a c} / N_{a}\right)+\beta_{2} \Delta \log \left(N_{a c t} / N_{c t}\right)+\beta_{3} \Delta \log \left(N^{*}{ }_{a d t} / N_{a t}\right)+ \\
& \beta_{4} \Delta \log \left(N^{*}{ }_{a h t} / N_{a t}\right)+\beta_{5} \Delta \log \left(N^{*}{ }_{a c t} / N_{a t}\right)+\tau_{t}+\delta_{a}+\epsilon_{a t}
\end{aligned}
$$

Finally, we include a relative supply variable based on years of potential experience rather than age. In other words, in this specification, we assume that college graduates compete with high school graduates who are typically about four years younger and enter the labor market in the same calendar year. We run the following regression in the last specification 


$$
\begin{aligned}
\Delta \log \left(W_{a c t} / W_{a t}\right)= & \beta_{1} \Delta \log \left(N_{a c} / N_{a}\right)+\beta_{2} \Delta \log \left(N_{a c t} / N_{c t}\right)+\beta_{3} \Delta \log \left(N_{x d t} / N_{x t}\right)+ \\
& \beta_{4} \Delta \log \left(N_{x h} / N_{x t}\right)+\beta_{5} \Delta \log \left(N_{x c t} / N_{x t}\right)+\tau_{t}+\delta_{a}+\epsilon_{a t}
\end{aligned}
$$

where $\mathrm{N}_{\mathrm{xt}}$ refers to the number of workers at a given year of potential experience.

[Table 2 here]

The regression results are reported in table 2. Column (1), which corresponds to our first specification, shows that the coefficient on the cohort college share variable is negative and statistically significant when only year dummies are included to control for relative supply. However, the relationship between cohort college share and the relative wage of college graduates becomes much weaker in our alternative specifications shown in columns (2) and (3). When we use the relative supply measure defined around age (column 2), the cohort college share variable is marginally significant (at the $10 \%$ significance level). The coefficient -.063 implies that the average premium is about 0.6 percent lower for a cohort that is 10 percent larger than average. When we use our alternative relative supply measure which is based on experience (column 3), the size of the coefficient on cohort college share variable is similar (-.060) although it is no longer significant.

A large literature on the effects of cohort size on earnings suggests that the wage penalty associated with being in a large cohort is especially pronounced upon labor market entry as suggested by Welch (1979) and Berger (1985). In the following section we examine whether our cohort quality effect also varies by age. We ran regressions as specified in (5) separately for young workers (between the ages 25 and 34) and for older workers (35 and older). The coefficients are reported in table 3. When we examine young workers only, our sample is 
reduced to 50 observations, and we find that the cohort quality variable is no longer significant. In the specification where we control for relative supply (column (2) of table 3), the cohort quality variable actually turns positive and is marginally significant. The cohort quality variable is much more robust and stable when we look at older workers (columns (3) and (4) of table 3). Aside from the fact that we have more observations for the older group, our assumption that workers at different ages are equally good substitutes for each other may be more valid for older workers, thus allowing us to more cleanly separate the quality and quantity effects.

[Table 3 here]

What is the economic significance of a coefficient such as (-.063)? What does this imply about the possible role of declining cohort quality in the 1970s and the 1980s? To answer this question, we use the coefficients from our cohort-level regressions (column (2)) to decompose total decade log changes in the relative wage of college graduates into components due to cohort quality, relative supply, and year effects. Overall, the relative wage of college graduates declined 5.3 percent during the $1970 \mathrm{~s}$ and increased 9.3 percent during the $1980 \mathrm{~s}$. Of the 5.3 percent decline over the 1970s, relative supply changes contributed a decline of 6.6 percent while an additional 2 percent decline was predicted by changes in the share of college. Aggregate time effects contributed an increase of 3.3 percent over this period. During the 1980 s, the impact of cohort quality was smaller. Aggregate time effects contributed an increase of 13.6 percent in the relative wage of college graduates. Relative supply changes contributed a decline of 3.3 percent and changes in college share contributed a decline of 1 percent. We conclude from table 2 that the cohort college share variable (our measure of cohort quality) is only weakly related to relative wages of college graduates once we control for relative supply. Overall, relative supply and time 
effects which may reflect aggregate demand changes in favor of college graduates account for most of the variation $(87 \%)$ in college wages. ${ }^{7}$

It may be useful to compare our results based on aggregate data to micro-level evidence from test score results. Recently, Murnane, Willett, and Levy (1995) reported test results from two successive cohorts using the National Longitudinal Survey 1972 and the High School and Beyond. They report average IRT-scaled math scores for college graduates and for the entire sample who finished high school. They find that between those two cohorts the college vs. overall test score differential increased 1.39 points, implying an increase in the average ability of college graduates between these two cohorts. Since the share of the cohort who attended college fell during this period, this is consistent with a negative relationship between size and average ability. According to their estimates, a 1 point increase in the math score results in a .013 increase in log hourly wages six years after the test. This results in a small predicted increase in the relative wage of college graduates between these two cohorts, generally in line with the small quality effects we find in our paper.

Finally, we end with the question that we first began with. What do we think of the enormous increase in the share of college graduates over time? Despite the fact that the cohort quality effect we estimate is small, nevertheless this would imply a large impact of declining cohort quality on college wage premium over 1940-1990 as the share of college graduates increased from 5 percent in 1940 to 23 percent in 1990 . We believe that this exercise would overstate the importance of cohort quality effects since the key assumption is that the distribution of ability is fixed over time. If we adopt a more broad definition of ability, as accumulated knowledge of potential college entrants, it seems very reasonable that ability would respond to 
changes in the demand for college graduates over the long run. Thus, our theoretical and empirical work presented in this paper may be more appropriate for examining short run changes where the distribution of ability can be described as fixed.

\section{Summary}

Using Census data, this paper documents the enormous increase in educational attainment of men and women in the U.S. during the 1940-1990 period. The paper examines whether the increase in number of college graduates lead to a decline in the average quality of college graduates and consequently affected their relative wages. The paper finds some weak evidence that college graduates from more educated cohorts receive a smaller college premium, holding constant other factors that also affect relative wages. ${ }^{8}$ These quality effects, however, appear to be small relative to the effects of demand and supply shocks and appear to have played only a minor in the recent fluctuations in the college premium.

\section{Appendix I}

In this section, we consider changes in the distribution of borrowing costs, r. For simplicity of presentation, we assume that the distributions of $r$ and $\lambda$ are orthogonal. Under that assumption, the joint density $\mathrm{h}(\mathrm{r}, \lambda)$ can be written as a product of marginal densities, $\mathrm{g}(\mathrm{r} \mid \delta) \mathrm{f}(\lambda)$. Here $\delta$ is the shift parameter specific to the density of interest rate, $g($.$) . A change in \delta$ induces changes in the number of college entrants and their average ability as the following. 
(A-1)

$$
\begin{gathered}
\partial N / \partial \delta=\int_{0}^{\bar{r}}\left[\int_{\lambda^{*}}^{1} f(\lambda) d \lambda\right] \partial g / \partial \delta d r=\int_{0}^{\bar{r}} N(r) \partial g / \partial \delta d r \\
\partial E_{c}(\lambda) / \partial \delta=1 / N \int_{0}^{\bar{r}}\left[\int_{\lambda^{*}}^{1}\left(\lambda-E_{c}(\lambda)\right) f(\lambda) d \lambda\right] \partial g / \partial \delta d r .
\end{gathered}
$$

In the above expression, $\mathrm{N}(\mathrm{r})$ is the number of college entrants facing the interest rate $\mathrm{r}$, and decreases with $r$. The impact on the number of college entrants depends on the correlation between $\mathrm{N}(\mathrm{r})$ and $\partial \mathrm{g} / \partial \delta$. Relaxation of borrowing constraints will tend to make $\partial \mathrm{g} / \partial \delta$ positive at low $r$ and negative at high $r$, and thus the number of college entrants will increase given such change in the distribution of $r$.

The impact on average ability depends on the correlation between $\int_{\lambda^{*}}(\lambda-\operatorname{Ec}(\lambda)) \mathrm{f}(\lambda) \mathrm{d} \lambda$ and $\partial \mathrm{g} / \partial \delta$. As $\operatorname{Ec}(\lambda)$ is the weight average of $\int_{\lambda^{*}} \lambda f(\lambda) \mathrm{d} \lambda$ where the weights are $\mathrm{g}(\mathrm{r} \mid \delta)$, the integral must have a negative value at low $r$ and a positive value at high $r$. As a result, the integral must increase with $\mathrm{r}$ initially. But at high $\mathrm{r}$, it may start to decline as $\lambda^{*}$ may exceed $\operatorname{Ec}(\lambda)$. Consequently, $\int_{\lambda^{*}}(\lambda-\operatorname{Ec}(\lambda)) \mathrm{f}(\lambda) \mathrm{d} \lambda$ has an inverted-U shape and the impact on average ability may vary with the extent of relaxation in borrowing constraints.

A general relaxation in borrowing constraints may be parameterized as positive values of $\partial \mathrm{g} / \partial \delta$ at low $\mathrm{r}$ and negative values of $\partial \mathrm{g} / \partial \delta$ at high $\mathrm{r}$. This is described in the left panel of the diagram below. In this case, $\int_{\lambda^{*}}(\lambda-\operatorname{Ec}(\lambda)) \mathrm{f}(\lambda) \mathrm{d} \lambda \cdot \partial \mathrm{g} / \partial \delta$ tends to have a negative value, and as a result, the average ability tends to decline. 
When the relaxation is of a very limited scope, the average ability may increase. This case is described in the right panel of the diagram. Suppose the borrowing constraints are relaxed only for those with extremely high interest rates. Then $\partial g / \partial \delta$ will be negative at such high interest rates and it will be positive at slightly lower interest rates. If this change in the

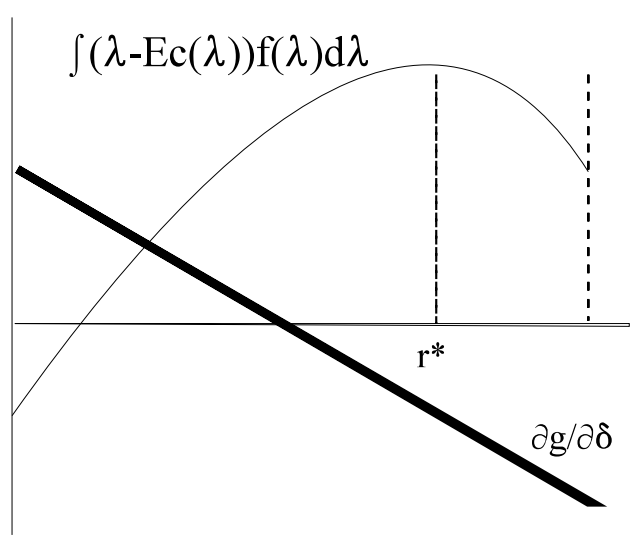

Case $1:$ Ability still declines

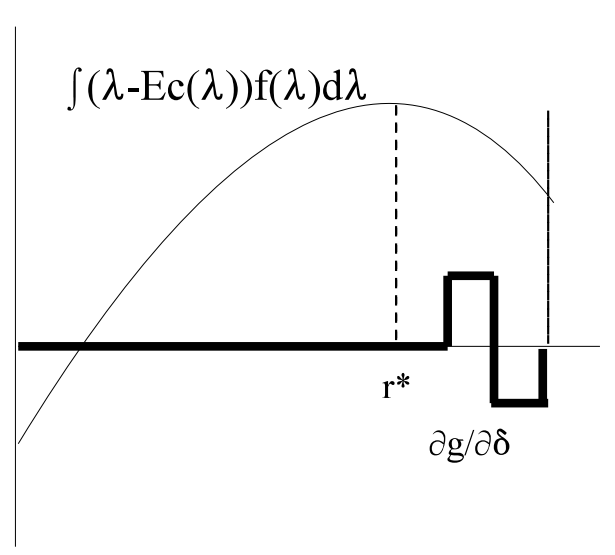

Case 2 : Ability increases

density $\mathrm{g}(\mathrm{r} \mid \delta)$ occurs where $\int_{\lambda^{*}}(\lambda-\operatorname{Ec}(\lambda)) \mathrm{f}(\lambda) \mathrm{d} \lambda$ decreases, a higher value of $\int_{\lambda^{*}}(\lambda-\operatorname{Ec}(\lambda)) \mathrm{f}(\lambda) \mathrm{d} \lambda$ is multiplied with positive $\partial \mathrm{g} / \partial \delta$ and a lower value of $\int_{\lambda^{*}}(\lambda-\operatorname{Ec}(\lambda)) \mathrm{f}(\lambda) \mathrm{d} \lambda$ is multiplied with negative $\partial g / \partial \delta$. Consequently, the average ability may increase.

The intuition behind these results is quite simple. The change in average ability depends on those newly entering college. In the first case, the change in density is assumed to induce more college enrollment among those who have faced relatively low interest rates. At the margin those individuals at low interest rates are less able individuals and their entry decreases average ability. In the second case, the change in density induces actions only at high interest rates. 


\section{REFERENCES}

Autor, D., L. Katz, and A.Krueger. "Computing Inequality: Have Computers Changed the Labor Market?” The Quarterly Journal of Economics 113(4), 1998, 1169-1214.

Becker, G. Human Capital and the Personal Distribution of Income. Ann Arbor: University of Michigan Press, 1967.

Berger, M. "The Effect of Cohort Size on Earnings Growth: A Re-examination of the Evidence." Journal of Political Economy 93(3), 1985, 561-73.

Blackburn, M., and D. Neumark. "Omitted-Ability Bias and the Increase in the Return to Schooling.” Journal of Labor Economics 11(3),1993, 521-544.

Cameron, S., and J. Heckman. "Life Cycle Schooling and Dynamic Selection Bias: Models and Evidence for Five Cohorts of American Males." Journal of Political Economy 106(2), 1998, 262-333.

Cameron, S., and C. Taber. "Borrowing Constraints and the Returns to Schooling." Manuscript, Northwestern University, 2000.

Card, D. "Earnings, Schooling, and Ability Revisited.” National Bureau of Economic Research Working Paper No.4832, 1994.

Card, D., and T. Lemieux. "Can Falling Supply Explain the Rising Return to College for Younger Men? A Cohort-Based Analysis?" National Bureau of Economic Research Working Paper No.7655, 2000.

Cawley, J., J. Heckman, and E. Vytlacil. "Cognitive Ability and the Rising Return to Education.” National Bureau of Economic Research Working Paper No. 6388, 1998.

Chay, K., and D. Lee. "Changes in Relative Wages in the 1980s: Returns to the Observed and Unobserved Skills and Black-White Wage Differentials." Manuscript, University of California-Berkeley, 1997.

Katz, L., and K. M. Murphy. "Changes in Relative Wages: 1963-1987: Supply and Demand Factors." The Quarterly Journal of Economics 107(1), 1992, 35-78.

Lang, K. "Ability Bias, Discount Rate Bias, and the Return to Education." Manuscript, Boston University, 1994. 
Murnane, R., J. Willett, and F. Levy. "The Growing Importance of Cognitive Skills in Wage Determination." Review of Economics and Statistics 77(2), 1995, 251-66.

Murphy, K. M., and F. Welch. "The Structure of Wages." The Quarterly Journal of Economics 107(1), 1992, 285-326.

Rosen, S. "Human Capital: Relations between Education and Earnings," in Frontiers of Quantitative Economics, edited by M. Intriligator. Amsterdam: North Holland, 1977.

Rosenbaum, D. “Ability, Educational Ranks, and Labor Market Trends: The Effect of Shifts in the Skill Composition of Educational Groups.” Manuscript, University of North CarolinaGreensboro, 1999.

Stanley, M.. "College Education and the Mid-century GI Bills." Quarterly Journal of Economics 118(2), 2003, 671-708.

Taubman, P., and T. Wales. Mental Ability and Higher Educational Attainment in the Twentieth Century. Berkeley: National Bureau of Economic Research and Carnegie Commission on Higher Education, 1972.

Topel, R.. "Factor Proportions and Relative Wages: The Supply-Side Determinants of Wage Inequality." Journal of Economic Perspectives 11(2), 1997, 55-74.

Welch, F. "Effects of Cohort Size on Earnings: the Baby Boom Babies' Financial Bust." Journal of Political Economy 87(5), 1979, S65-S97.

Willis, R., and S. Rosen. "Education and Self-Selection." Journal of Political Economy 87(5), 1979, S7-S36. 
FIGURE 1 Educational Attainment by Birth-Year Cohort: Males

FIGURE 2 Educational Attainment by Birth-Year Cohort: Females

FIGURE 3 Share of 20-24 Year Olds in School or College Graduates

FIGURE 4

FIGURE 5 Log Change in Relative Wage and College Share

FIGURE 6 Log Change in Relative Wage and College Share 


\section{$\underline{\text { Endnotes }}$}

*We thank two anonymous referees for comments and suggestions on earlier drafts.

Juhn: Department of Economics, University of Houston, Houston, TX 77204-5882. Phone 713743-3823, Fax 713-743-3798, E-mail cjuhn@uh.edu.

Kim: School of Economics, Seoul National University, Seoul 1510742, Korea. Phone 82-2-8806364, Fax 82-2-886-4231, E-mail dikim@plaza.snu.ac.kr.

Vella: Department of Economics, European University Institute, Villa San Paolo, Via della Piazzuola 43, 50133, Florence, Italy. Phone 39-055-4685-952/954, Fax 39-055-4685-902, E-mail frank.vella@iue.it.

${ }^{1}$ Our quality effects are smaller than those reported by Rosenbaum (1999) who examines the rise in the college premium with and without ability controls. While both papers use cohort-specific educational attainments to proxy for ability changes, the difference in our results may be due to the fact that we focus exclusively on changes in ability composition in this paper while he also allows for changes in returns to ability over time.

${ }^{2}$ The 1990 Census questionnaire changed emphasis from grades attended to degree obtained. In order to make the 1990 data comparable to the earlier years, we imputed the distribution of grades completed by reported education on the 1990 Census using the matched March samples for 1991-92. Details of this imputation procedure are available from the authors.

${ }^{3}$ Reporting of education on the March CPS switched between the 1991 and the 1992 surveys. We again used the March matched samples from 1991-92 to calculate the distribution of grades completed and school enrollment status by the new reported education variable.

${ }^{4}$ Although our theoretical model considers declines in cohort quality arising from changing ability compositions, the decline in quality may also arise from sudden increases in enrollment 
reducing the quality of college education when resources are relatively fixed in the short run. Our empirical work can also address these types of changes in cohort quality.

${ }^{5}$ Of course, an alternative set-up would be to assume that the return, R, does not vary with ability but the cost of going to college is negatively related to ability.

${ }^{6}$ Cameron and Heckman (1998) and Cameron and Taber (2000) conclude that credit constraints are less important than permanent income and family background characteristics in explaining schooling attainment. Both papers find that borrowing constraints are not empirically important, at least for the recent cohorts. These papers suggest that short-term tuition subsidies are unlikely to encourage enrollment of high ability students from lower income families.

${ }^{7}$ Recently, a number of papers have examined whether the recent increase in the college premium was due to rising returns to raw ability rather than skills acquired in college (see, for example, Blackburn and Neumark (1993), Chay and Lee (1997), Cawley, Heckman and Vytlacil (1998)). While this is an important question in its own right, our focus in this paper is on wage effects due to changes in ability composition rather than changing returns. In our empirical work, both increases in returns to ability and college skills are captured by the aggregate time effects reported above.

${ }^{8}$ In earlier versions, we also examined the occupation distribution of college graduates from different birth cohorts. We found some evidence, particularly in the more recent data, that college graduates from more educated cohorts were less likely to be working in the most skilled occupations, where occupations are ranked based on the average wage in the occupation. These results are available upon request from the authors. 
TABLE 1

Education Distribution for Men 1940-1990

$\begin{array}{lrrrrrr}\text { Years of Schooling } & 1940 & 1950 & 1960 & 1970 & 1980 & 1990 \\ <12 & 73.6 & 63.3 & 54.5 & 39.7 & 25.4 & 18.6 \\ =12 & 15.3 & 21.2 & 25.1 & 32.1 & 35.1 & 35.7 \\ 13-15 & 5.8 & 8.3 & 10.2 & 13.9 & 19.3 & 23.1 \\ 16+ & 5.4 & 7.3 & 10.2 & 14.3 & 20.2 & 22.6\end{array}$

Education Distribution for Women 1940-1990

Years of Schooling $19401950 \quad 19601970 \quad 19801990$

$\begin{array}{llllllll}<12 & 70.0 & 59.0 & 51.1 & 38.3 & 25.4 & 17.7\end{array}$

$\begin{array}{lllllll}=12 & 19.7 & 27.4 & 32.8 & 39.7 & 42.2 & 39.7\end{array}$

$\begin{array}{lllllllll}13-15 & 6.5 & 8.4 & 10.0 & 13.2 & 18.7 & 24.1\end{array}$

$\begin{array}{lllllll}16+ & 3.8 & 5.2 & 6.1 & 8.8 & 13.6 & 18.6\end{array}$

Source: 1940-1990 PUMS (1\% samples). The samples include men and women aged $20-64$. 
Effects of Cohort-Specific College Share on Wages of College Graduate Men

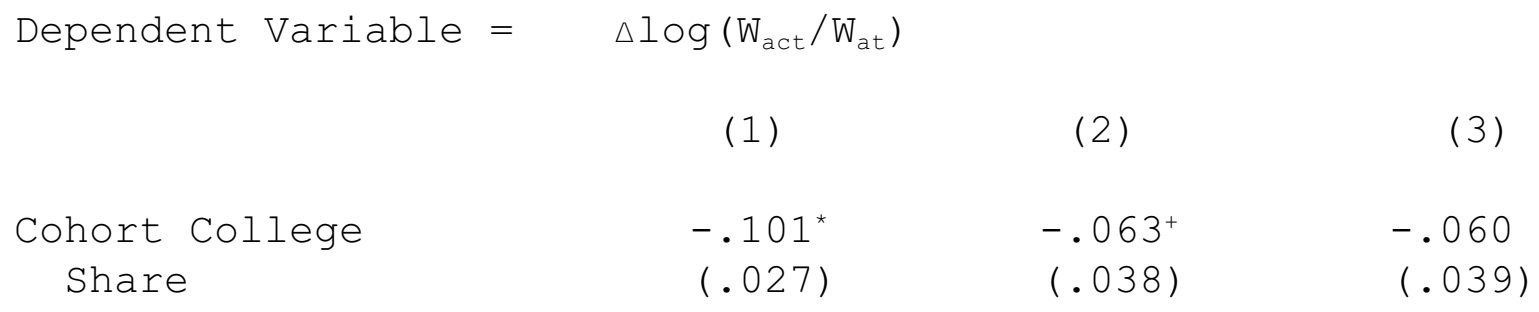

Relative Supply

$<12$ Years

12-15 Years

$16+$ Years

Cohort Size

$\begin{array}{ccc}-- & .056^{+} & .026 \\ & (.030) & (.030) \\ -- & -.027 & .031 \\ & (.040) & (.037) \\ -- & -.075^{+} & -.037 \\ & (.040) & (.032)\end{array}$

$-.042^{*}$

$-.000$

$-.025$

(.019)

$(.025)$

(.022)

Year Dummies Included

yes yes

yes yes

yes

Age-group Dummies Included

no yes

yes

Relative supply (age)

no

no

yes

Number of Obs. 200

Source: 1940-1990 Census PUMS (1\% sample). The sample includes $25-64$ year old men who were working during the survey week.

Note: Wage Regressions also include control for cohort size, 5 year dummy variables and 2 age dummy variables for young and middle age workers.

Cohort College Share $=\Delta \log \left(\mathrm{N}_{\mathrm{ac}} / \mathrm{N}_{\mathrm{a}}\right)$. Cohort Size $=\Delta \log \left(\mathrm{N}_{\mathrm{act}} / \mathrm{N}_{\mathrm{ct}}\right)$. Relative Supply in column (2) is defined as $N^{*}{ }_{a e t}=\left\{1 / 9 *\left(N_{a-2, e t}+2 * N_{a-1, e t}+3 * N_{a e t}+2 * N_{a+1, e t}+N_{a+2, e t}\right)\right\} / N_{a t}$ where e refers to the education group- high school dropouts, high school graduates, or college graduates. Relative supply in column (3) is $\mathrm{N}_{\mathrm{xet}} / \mathrm{N}_{\mathrm{xt}} \mathrm{where}$ $x$ refers to years of potential experience rather than age. 


\begin{tabular}{|c|c|c|c|c|}
\hline \multirow[t]{3}{*}{ Dependent Variable $=$} & \multicolumn{3}{|c|}{$\Delta \log \left(W_{a c t} / W_{a t}\right)$} & \\
\hline & \multicolumn{2}{|c|}{ Workers Aged $<35$} & \multicolumn{2}{|c|}{$\underline{\text { Workers }>=35}$} \\
\hline & (1) & (2) & (3) & $(4)$ \\
\hline $\begin{array}{l}\text { Cohort College } \\
\text { Share }\end{array}$ & $\begin{array}{l}-.039 \\
(.057)\end{array}$ & $\begin{array}{l}.188^{+} \\
(.098)\end{array}$ & $\begin{array}{r}-.068^{+} \\
(.036)\end{array}$ & $\begin{array}{l}-.075 \\
(.048)\end{array}$ \\
\hline \multicolumn{5}{|l|}{ Relative Supply } \\
\hline$<12$ Years & -- & $\begin{array}{l}.222 \\
(.161)\end{array}$ & -- & $\begin{array}{l}.014 \\
(.056)\end{array}$ \\
\hline $12-15$ Years & -- & .542 & -- & $\begin{array}{r}-.068 \\
(.040)\end{array}$ \\
\hline $16+$ Years & -- & $\begin{array}{l}-.243 \\
(.271)\end{array}$ & -- & $\begin{array}{r}-.043 \\
(.048)\end{array}$ \\
\hline Cohort Size & $\begin{array}{l}.025 \\
(.054)\end{array}$ & $\begin{array}{l}.094 \\
(.069)\end{array}$ & $\begin{array}{r}-.052^{+} \\
(.029)\end{array}$ & $\begin{array}{l}-.037 \\
(.035)\end{array}$ \\
\hline Year Dummies & yes & yes & yes & yes \\
\hline Age Dummies & no & no & no & no \\
\hline Relative supply (age) & no & yes & no & yes \\
\hline Number of Obs. & 50 & 50 & 150 & 150 \\
\hline
\end{tabular}

Source: 1940-1990 Census PUMS (1\% sample). The sample includes 25-64 year old men who were working during the survey week.

Note: See table 


\section{FIGURE 1}



\section{FIGURE 2}
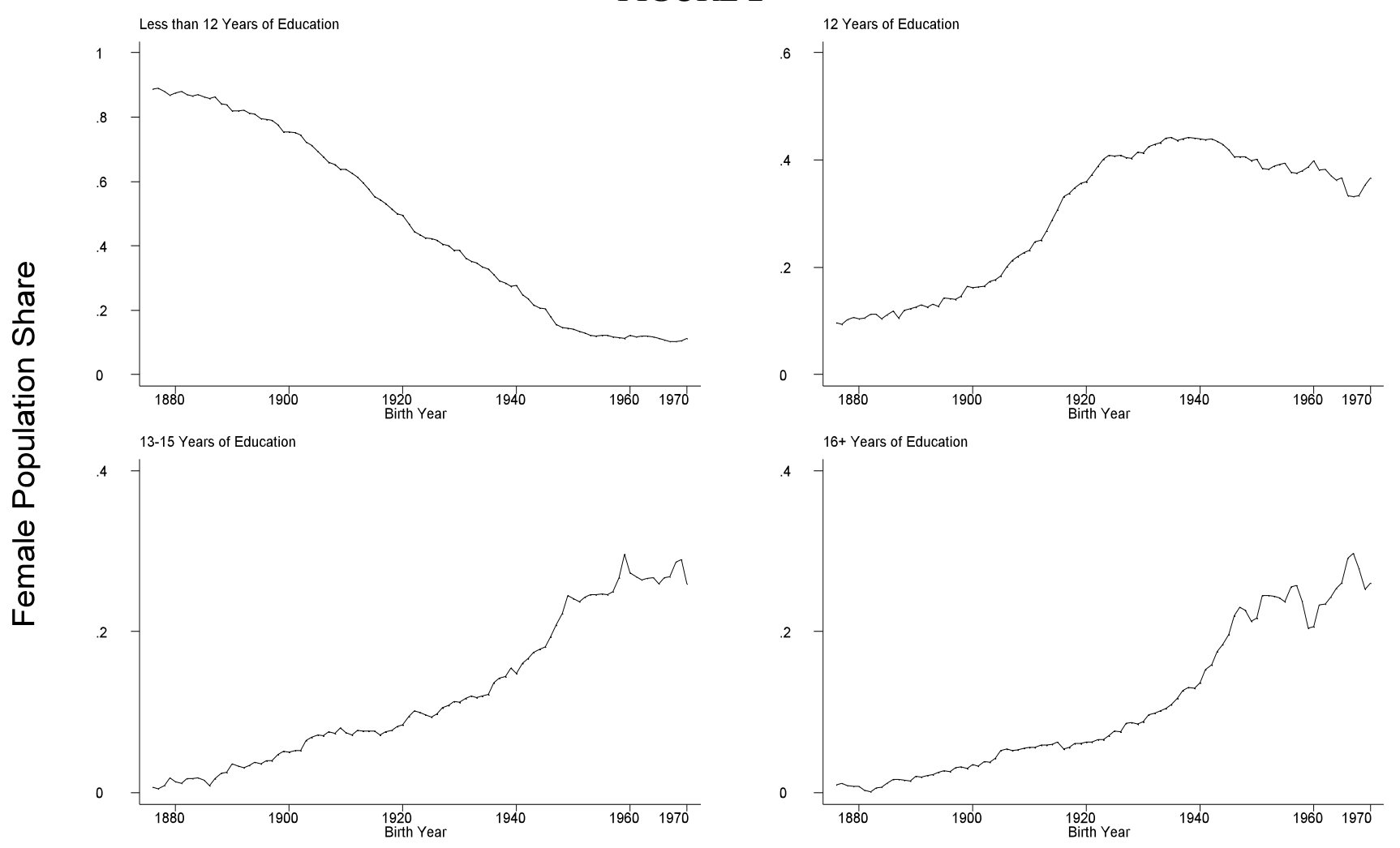


\section{FIGURE 3}
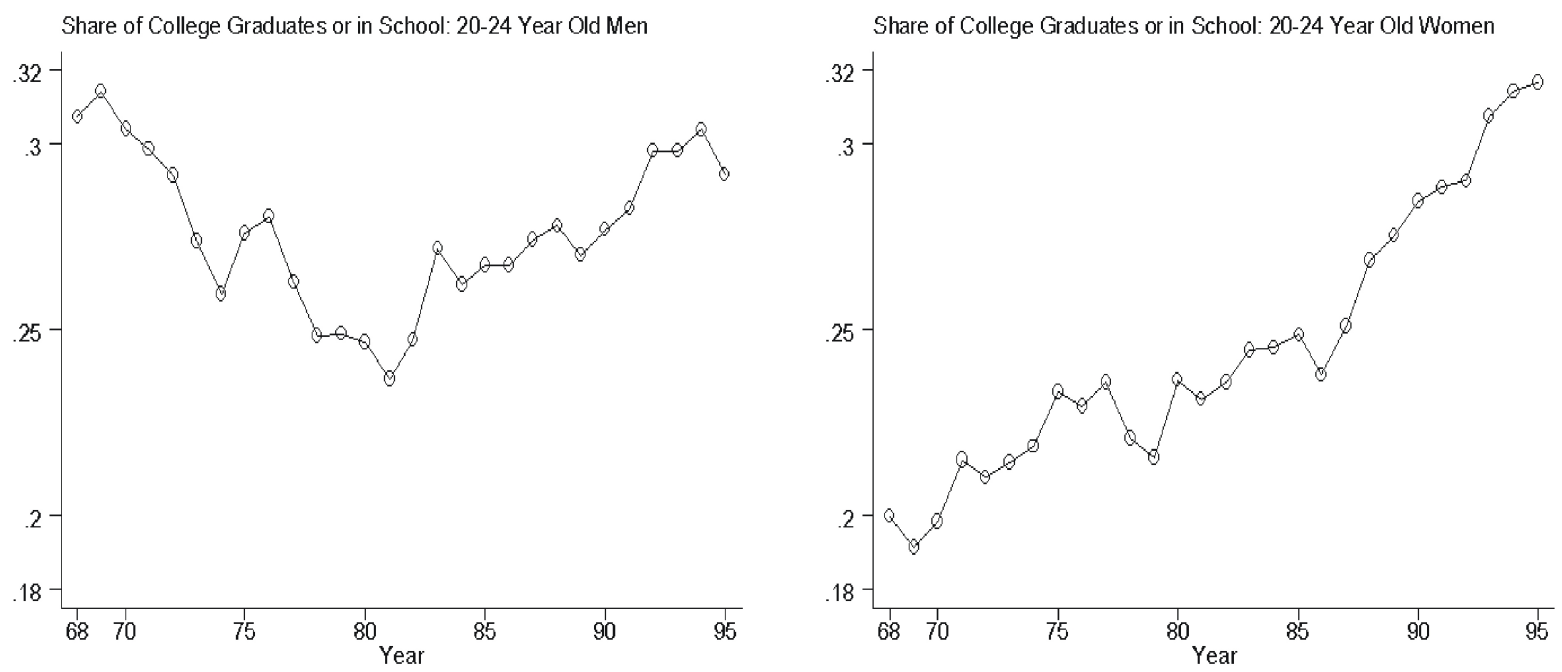


\section{FIGURE 4}

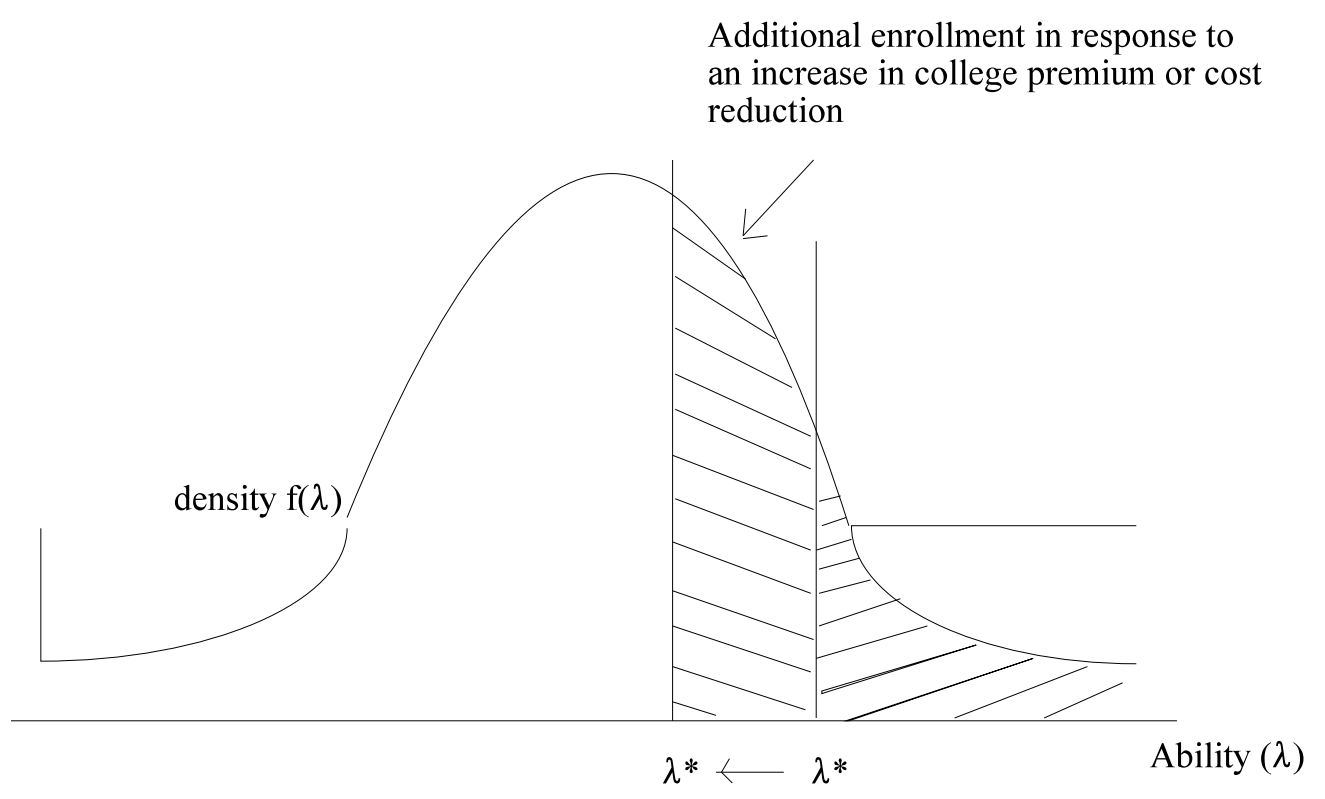




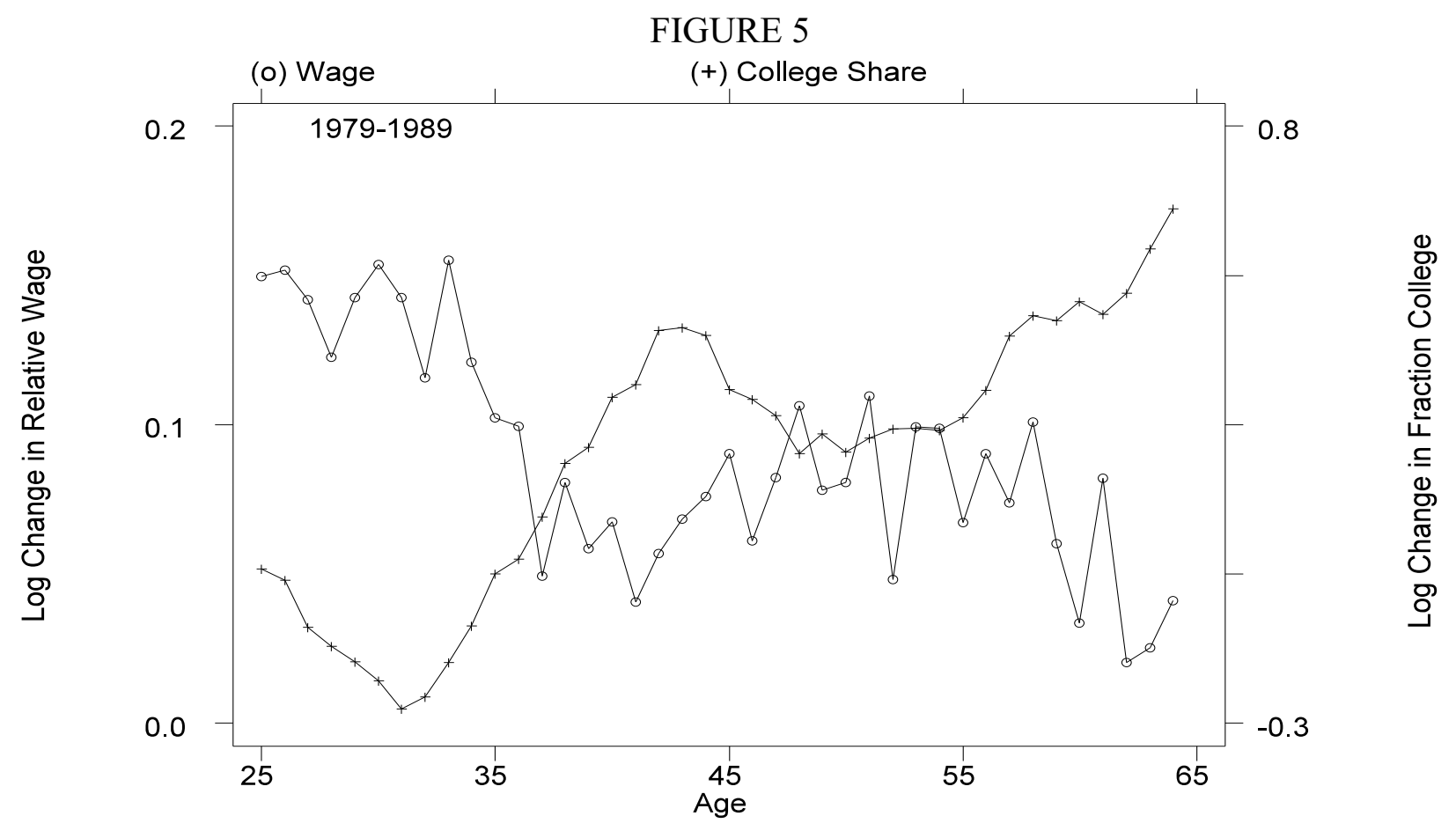




\section{FIGURE 6}
